\title{
Proyecto ComunicArte: Arte y palabras para aprender español y participar en la ciudad. Una propuesta didáctica
}

\author{
Concepción FRANCOS MALDONADO \\ fmaldonadoc@yahoo.es \\ Aula de Inmersión Lingüística. IES Alfonso II.
}

Recibido: marzo 2014

Aceptado: julio 2014

\section{RESUMEN}

La propuesta que presentamos se desarrolla en un contexto escolar multicultural y multilingüe, en educación secundaria, con alumnado recién llegado a España procedente de diferentes continentes.

A partir de un marco teórico interdisciplinar, se plantea el aprendizaje de español segunda lengua para desarrollar la competencia comunicativa conversacional, académica e intercultural y sensibilizar en el plurilingüismo. Desde una pedagogía que acompaña y escucha a los sujetos con su voz y biografía, se establecen conexiones entre lo subjetivo, referentes culturales y lingüísticos del alumnado del aula, los entornos cotidianos y lo escolar.

Recurrimos al retrato y al autorretrato como texto escrito y como expresión plástica. Para ello nos acercamos a cómo mirar y leer una obra de arte a través de obras de algunos artistas y el arte de diferentes culturas; se realizan autorretratos, lecturas interculturales, en algunos casos bilingües en español y en otras lenguas del aula, y se trabaja la escritura de textos descriptivos, poéticos, informativos con contenidos de algunas áreas curriculares, propiciando el diálogo entre culturas y la sensibilización sobre la diversidad lingüística.

Palabras clave: Leer, escribir, diversidad lingüística, plurilingüismo, diversidad cultural, competencia comunicativa académica e intercultural, arte.

\section{ComunicArte Project: Art and words for learning Spanish and to participate in the city from a intercultural approach. A didactic proposal}

\begin{abstract}
Our proposal is developed in a multicultural and multilingual school contexts, in secondary education, with new students to Spain from different continents.

Based on an interdisciplinary theoretical framework, there is the Spanish second language learning to develop conversational communicative competence, academic and intercultural awareness in multilingualism. From a pedagogy that accompanies and listen to his voice and subjects with biography, connections are established between subjective, cultural references and linguistic students of the classroom, school and everyday environments.
\end{abstract}


We look to the portrait and self-portrait as a written text and as artistic expression .To do this we approach how to look and read a work of art through works of some artists and the art of different cultures are made self-portraits, intercultural readings in some cases bilingual in Spanish and other languages in the classroom, and work writing descriptive texts, poetic, informative, with contents of some curriculum areas, fostering dialogue between cultures and awareness of linguistic diversity.

Keywords: Reading, writing, linguistic diversity, multilingualism, cultural, academic and intercultural communicative competence, art.

\section{Projet Comunic Arte: De l'art et des mots dans l'apprentissage de l'espagnol et pour la participation dans la cité dans une approche interculturelle. Une proposition didactique}

\section{RÉSUMÉ}

Notre proposition est développée dans un contexte scolair multiculturel et multilingue, dans l'enseignement secondaire, avec les élèves nouveaux arrivants à l'Espagne de différents continents .

L'objectif est d'apprendre une langue seconde (espàgnol) pour développer la compétence communicative conversationnel, académique et interculturelle et de sensibilisation dans le multilinguisme.

Nous nous tournons vers le portrait et l'autoportrait comme un texte écrit et d'expression artistique . Pour ce faire, nous abordons la façon de regarder et de lire une œuvre d'art à travers les œuvres de certains artistes et de l'art des différentes cultures; autoportraits, lectures interculturelles sont prises, dans certains cas, bilingue en espagnol et autres langues dans la salle de classe, et le travail écriture descriptive, poésie, textes informatifs, avec du matériel de certains domaines d'études, pour favoriser le dialogue entre les cultures et la conscience de la diversité linguistique .

Mots-clés: La lecture, l'écriture, la diversité linguistique, le plurilinguisme, la diversité culturelle, la compétence en communication interculturelle et académique, l'art.

SUMARIO: 1. Introducción. 2. Algunas claves teóricas. 3. Contexto.4. Objetivos. 5. Metodología. 6. ComunicArte: Arte y palabras para comunicarse. 6.1. Desarrollo de la actividad. 6.2. Criterios y procedimientos de evaluación. 7. Consideraciones finales. 8. Bibliografía. Anexo.

Lo que debe oír el inmigrante en este siglo nuevo, lo que necesita que le digan con palabras, con comportamientos, con decisiones políticas[...]:Tienes el derecho y el deber de estudiar a fondo nuestra lengua, pero también tienes el derecho y el deber de no olvidar tu lengua de origen, porque nosotros, que somos tu nación adoptiva, necesitamos contar entre nosotros con personas que compartan nuestros valores, que comprendan nuestras preocupaciones y que hablen el turco, el vietnamita, el ruso, el árabe, el armenio, el swahili, o el urdu, todas las lenguas de Europa, Asia, África, todas sin excepción, para que podamos conseguir que nos oigan todos los pueblos del planeta. Entre ellos y nosotros serás, en todos los ámbitos- la cultura, la política, el comercio-, un intermediario insustituible. (Maalouf,A., 2009:294,295) 


\section{INTRODUCCIÓN}

Vivimos en sociedades multiculturales y multilingües ${ }^{1}$, y esa realidad no es un ente abstracto, sino que está constituida por personas con nombre, ilusiones, sueños, historia, vivencias, emociones,... ¿cómo incorporar toda esa vida al currículum, a las aulas? Freire proponía ligar la lectura de la palabra a la lectura del mundo.

En este sentido, en el aula buscamos plantear propuestas que incidan en cómo incorporar lenguas maternas, los bagajes culturales y experienciales del alumnado, la colaboración de las familias y el entorno como recurso para el aprendizaje de una nueva lengua tanto en habilidades conversacionales como académicas, y la competencia comunicativa intercultural, de modo que se pongan las bases para el éxito académico y a la vez para la reflexión sobre la construcción de sus identidades y el descubrimiento y la participación en el entorno multicultural en el que vivimos.

Con este texto queremos dar cuenta de la experiencia realizada y reflexionar sobre algunos de los planteamientos teóricos en los que se basa. Para ello, apuntamos algunas claves teóricas, exponemos los objetivos que nos proponemos; en el apartado de desarrollo explicitamos cómo se lleva a cabo y por último exponemos algunas consideraciones finales.

\section{ALGUNAS CLAVES TEÓRICAS}

Partimos de un marco teórico interdisciplinar: el enfoque inclusivo, que destaca la relevancia de la vinculación de los contextos familiares, escolares y de la comunidad para potenciar el éxito académico, y, especialmente, el desarrollo de personas libres ; el enfoque intercultural-antirracista, que hace hincapié en las relaciones de dominación de países pobres hacia los países ricos; asimismo, explica causas de las migraciones y demanda la igualdad de oportunidades para todos los grupos étnicos. Estas son premisas básicas para ir adquiriendo la competencia intercultural, que se posibilitará si se reconocen los acervos culturales e identitarios de las personas (Taylor, 1993), si se facilita el tejer los bagajes previos con los nuevos de la sociedad en la que se vive en ese momento y se potencian las identidades múltiples desde las aulas y desde el entorno. Desde las primeras ofreciendo posibilidades para que todas las identidades, que están en permanente construcción, fluyan y formen parte de los aprendizajes, abriendo caminos hacia currículos interculturales (Banks, 1992; Coelho, 2005, etc.) en los que estén presentes las aportaciones a la Humanidad de las diferentes culturas. Desde el

${ }^{1}$ El MCER (2002) diferencia entre multilingüismo: coexistencia de varias lenguas en una sociedad determinada. Y plurilingüismo: presencia simultánea de dos o más lenguas en la competencia comunicativa de un individuo y a la interrelación que se establece entre ellas. 
entorno entendido en sentido amplio: el lugar donde se vive, los gobiernos, las instituciones, pues como dice Kymlicka :

[...] es importante que los gobiernos se esfuercen para que los hijos de los inmigrantes se sientan "en casa" en la cultura mayoritaria, para sentir que esta es " su cultura" [...] Ellos (los niños) son quienes más sufrirán con la marginación, ya que sus progenitores, cuando menos, tuvieron la ventaja de crecer como plenos participantes en una cultura societal en su país, y pueden inspirarse en esto para añadir significado a las prácticas que intentan mantener, de forma reducida y fragmentaria en la nueva tierra. Los niños tienen el derecho de crecer como plenos participantes en una cultura societal [...] (Kymlicka,1996:136-137)

Otros autores, como García Canclini (1990), consideran algunos espacios, como las ciudades, lugares privilegiados para la interculturalidad. Las instituciones y servicios públicos (bibliotecas, museos, etc.) son elementos importantes en la construcción de sociedades interculturales. Algunos ejemplos de sus posibilidades los recogen documentos internacionales como el Manifiesto de la UNESCO para las bibliotecas públicas, o proyectos europeos como Museos y diálogo intercultural (2009); por lo que hay que facilitar la democratización del acceso a estos servicios, pero también por su papel de mediación cultural según los planteamientos de Caune:

La primera observación consiste en afirmar que el proceso de mediación es consustancial a las relaciones entre el ser humano y su entorno social. La forma simbólica, el fenómeno significante, se encuentra en el corazón de la identidad humana. Las palabras, las expresiones, las prácticas simbólicas son mediaciones culturales, lo que equivale a decir que la mediación cultural, la que se apoya en las formas simbólicas, es una característica del ser humano, en su relación con el otro(Caune, 2009:21)

En ese interés por los espacios públicos y en su papel de mediadores culturales y simbólicos insiste Benach (2008:93) cuando defiende que los espacios públicos deben dotarse de identidades múltiples, de poder simbólico, de significado para las personas que los usan.

Desde la enseñanza-aprendizaje de lenguas, en las últimas décadas se viene planteando la estrecha vinculación entre lengua y cultura, así autores como Byram y Zarate (1994), acuñan el término de competencia comunicativa intercultural, y hablante intercultural, este último se refiere a quien es capaz de actuar de mediador entre personas de diferentes culturas. El MCER (Marco Común Europeo de Referencia para las lenguas) aunque habla solo de la consciencia intercultural, también hace referencia a la persona que aprende como interlocutor complejo en cuanto agente social que domina varias lenguas y con experiencia en varias culturas. 
Igualmente, tenemos en cuenta la perspectiva constructivista, que fomenta la interacción y la participación y da al sujeto un papel activo en la construcción de los aprendizajes, de las identidades.

Por otra parte, nos apoyamos en las aportaciones de investigaciones sobre lectura y escritura en los aspectos de leer para aprender contenidos curriculares (Jolibert, 2001;Tolchinsky y Simó, 2001; Nemirovsky,2009,etc.),y leer para imaginar y para vincularse empáticamente con formas de sentir y de pensar de diferentes culturas. Otra clave es la pedagogía de la multialfabetización de Cummis (2005), que parte de la transferencia de lenguas, y que se apoya, entre otras herramientas, en textos de identidad en varias lenguas. Se propone al alumnado la creación de manifestaciones literarias y artísticas en las diferentes lenguas que conocen, lo cual facilita aunar lo cognitivo y lo emocional, tan imbricados en los aprendizajes ( Vila, 2006).Y finalmente, tenemos presentes las investigaciones en educación artística y diversidad cultural.

Teniendo en cuenta estas claves realizamos nuestra propuesta, relacionando los bagajes del alumnado con diferentes áreas y temas del currículo y con un espacio de la ciudad que en este caso es el museo.

\section{CONTEXTO}

El contexto en el que se desarrolla la propuesta es contexto escolar en educación secundaria, en aulas multiculturales, con alumnado recién llegado procedente de diferentes continentes. En este contexto se aborda la enseñanza-aprendizaje del español segunda lengua desde la competencia comunicativa conversacional, pero también es necesario que el alumnado se acerque a la competencia académica y a la intercultural, aunque sabemos que para estas dos últimas el tiempo de adquisición es más largo. También está presente el plurilingüismo.

El alumnado tiene edades entre los 12 y los 16 años, con una base curricular muy diversa y con situaciones familiares también muy distintas.

\section{OBJETIVOS}

Partiendo de que quienes aprenden son sujetos biográficos, como decíamos más arriba, que aprenden en las aulas, en el mundo y de sí mismos, los objetivos de la propuesta intentan recoger diferentes dimensiones:

- Crear contextos y propuestas que vinculen identidades, bagajes culturales, lingüísticos y experienciales, con el currículum.

- Desarrollar la competencia comunicativa conversacional, académica, intercultural y plurilingüe.

- Leer y escribir para aprender contenidos curriculares, acercarse al arte, a la poesía y a la diversidad cultural.

- Aunar diferentes lenguajes: verbal y visual; la palabra y el arte. 
- Conocer servicios culturales de la ciudad y participar en ellos. El Museo como espacio de diálogo intercultural

\section{METODOLOGÍA}

Se basa en el enfoque comunicativo, intercultural, por proyectos y por tareas a partir de un marco teórico interdisciplinar.

Nos detenemos un momento en algunas de las características del planteamiento de trabajo por proyectos, poniendo el "zoom" en este caso en los proyectos en el campo de las lenguas, nos basamos en Camps et al.(2003):

- Prioriza actividades expresivas y comunicativas y el trabajo colaborativo. En el presente proyecto se necesita compartir información para elaborar unos textos finales, escritos y plásticos, que se comparten en grupo clase y con otros públicos.

- El uso de la lengua es funcional (en el proyecto que presentamos, la búsqueda, selección, lectura y comprensión de información de las diferentes fuentes se hace para poder escribir los diferentes textos que se presentan al grupo clase y poder realizar el autorretrato)

- Se integran las cuatro habilidades lingüísticas: hablar, escuchar, leer, escribir. Se habla para escribir, para mejorar la escritura a través de las aportaciones de los demás, se lee para escribir, y se escribe para presentar un texto oral al grupo clase.

- Facilita las relaciones interdisciplinares para trabajar lengua y contenidos referentes a las diferentes áreas del currículo. En este caso se aprenden conceptos y léxico de Ciencias Sociales y Ciencias Naturales como un recurso para expresar identidades, sensaciones, emociones, etc.

A lo largo del proceso de realización del proyecto son muy importantes las interacciones orales que se realizan entre compañeros/as y con la profesora para el desarrollo del texto, tanto en los aspectos de estructuración del mismo como formales (ortografía, etc.,), para ver si los lectores comprenden el texto y para interiorizar sus características y cómo se elabora.

Las TIC (tecnologías de la información y de la comunicación) y las TAC ( tecnologías del aprendizaje y del conocimiento) también son una herramienta importante en el proceso de escribir, pues en el primer momento de escritura del texto, cuando se escribe el borrador, la atención está puesta en qué decir y cómo decirlo, y en un segundo momento se hacen las correcciones de ortografía, de expresión, de reducción o ampliación del texto, etc. El primer borrador se conserva 
para ver el contraste con el texto final y cómo mejoró su calidad, logrando así que el alumnado asuma la auténtica tarea de escribir (Nemirovsky,2004), aunque en un primer momento preguntan que para qué hay que guardar el texto que tiene errores.

\section{COMUNICARTE: ARTE Y PALABRAS PARA COMUNICARSE}

La alfabetización del s. XXI va mucho más allá de aprender a leer y escribir, pues comunicar/se en las sociedades actuales, supone, más que nunca, tener en cuenta que las lenguas llevan implícitas diferentes formas de ver el mundo y que, también hay aspectos comunes a todas ellas, como la misma necesidad de comunicar, de compartir emociones, entre otras. Las diferentes formas de expresión artística (artes visuales, danza, etc...) proporcionan muchas posibilidades de comunicar mediante diferentes tipos de textos. Unir palabra y arte para comunicarse es lo que tratamos de entretejer en este proyecto.

Tarea: Presentarse (al grupo clase en un primer momento, a otros públicos después) mediante un dibujo del propio retrato y textos descriptivos y poéticos, teniendo en cuenta la diversidad cultural y movimientos artísticos.

\subsection{Desarrollo de la actividad}

En el tema de las presentaciones y las descripciones, el proyecto de trabajo es presentarse en una segunda lengua, a través de diferentes textos: descriptivo, poético, plástico realizando el dibujo del autorretrato, basándonos en la teoría de la multialfabetización que citábamos más arriba y en la propia experiencia de cómo el lenguaje artístico (literario, plástico) potencia la capacidad y el deseo de expresarse.

Reflexionamos sobre la propia identidad, para lo que planteamos la pregunta ¿Quién soy? El alumnado aprende a dar sus datos personales y a descubrir algunos fondos de identidad que pueden ser geográficos, culturales, sociales. Para ayudar a expresar dichos fondos también se establecen relaciones con otras áreas del currículo, como las Ciencias Sociales, a través del campo semántico de lugares y accidentes geográficos: continente, país, ciudad, pueblo, océano, mar, lago, río, playa, montaña; y también lenguas, instrumentos musicales, etc. Y con las Ciencias Naturales, mediante el léxico de los sentidos, sus órganos y las acciones asociadas a los mismos ( tabla 1), las sensaciones y las emociones.

Para empezar, trabajamos la escritura de textos descriptivos, a partir de los datos personales y de la descripción física y de carácter. Primero realizamos diversas actividades orales a partir de un guión que incluye preguntas sobre información personal (¿Cómo te llamas? ¿Cómo te apellidas?,...).Reflexionamos sobre los recursos lingüísticos que necesitamos: verbos llamarse, ser,...la nacionalidad, los números, para decir la edad, etc....Se preguntan los datos personales por parejas, después dan la información oralmente sobre sí mismos o presentando al compañero/a, y posteriormente se escribe un texto con dichos datos. A 
continuación trabajamos campos semánticos relacionados con las Ciencias Sociales: lugares y accidentes geográficos (continente, país, ciudad, pueblo, montaña, océano, mar, río, isla, ....) para expresar pertenencias identitarias, para acercarnos al léxico básico específico de este área académica, etc.

Otra pregunta que planteamos es ¿Cómo soy? Para poder contestarla se aborda la descripción de rasgos físicos y de carácter. Con las descripciones físicas y de carácter se sigue el mismo proceso que hicimos con los datos personales. Ponemos en común qué recursos lingüísticos se necesitan para describir retratos: verbos (ser, tener, estar, llevar. gustar,....), adjetivos para la descripción de personas en aspectos físicos y de carácter; los colores; la concordancia...También realizamos lecturas interculturales con diferentes referentes culturales y lingüísticos que recogen descripciones de personas, en algunos casos bilingües en español y en otras lenguas del aula como el cuento La opinión de los demás en chino y en español. Es uno de los recursos que utilizamos para fomentar el plurilingüismo. A partir de todos esos elementos cada alumno/a escribe diferentes tipos de texto, entre otros:Un texto de presentación y descriptivo:

Me 1lamo Oussama. Soy de Marruecos. Tengo 14 años, hablo árabe, un poco francés y un poco de español. Soy de talla mediana. Soy moreno, tengo el pelo negro y los ojos marrones y la nariz mediana, tengo la frente pequeña las cejas negras. Soy delgado. Me gusta comer patatas fritas y cuscus y arroz, hamburguesas y muchas cosas. Me gusta vestir pantalón largo o corto camiseta o camisa corta o larga y me gusta poner zapatos o deportivas. Me gusta el fútbol, el baloncesto, nadar y correr. Me gusta escuchar música de Don amor o Mattayas.

Oussama, Marruecos.

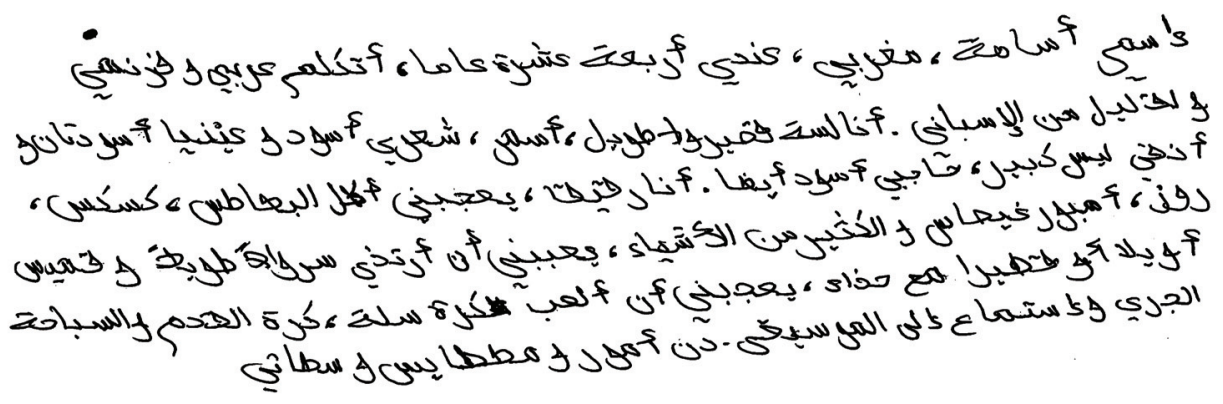

Imagen número 1 Oussama, Marruecos.

Se realizan algunas actividades con los nombres: Cómo se escribe cada nombre en las diferentes lenguas maternas del alumnado de la clase, cómo se pronuncia, si tienen un significado, quién eligió su nombre, etc. A partir de la lectura de un fragmento del libro Anne aquí, Sélima allí, de Marie Féraud, en el que la protagonista cambia de nombre y dice por qué, se pregunta al alumnado si cambiaría de nombre, como la protagonista, y por qué. Trabajar con los nombres es 
una forma de valorar la diversidad cultural, de ver elementos identitarios, de valorar la propia cultura y el plurilingüismo.

Después se propone la escritura de un texto poético en acróstico. Escriben su nombre en acróstico y con cada letra escriben una frase que expresa un rasgo de sí mismos con el que se identifican, un deseo de ser, etc... Lo traducen a su lengua materna y les permite darse cuenta de la relación y la diferencia entre las palabras de una y otra lengua.

Un ejemplo de acrósticos con su nombre:

Guapo y simpático

Único en comer patatas

Imbatible en estudiar

Legítimo y amable

Honesto y agradable

Enérgico y eléctrico

Rebelde con los malos.

Médico es la profesión que quiero ser

Elegante en el vestir. (Guilherme, Brasil).

En portugués brasileño:

Bonito e amigável

Exclusivo para comer batatas fritas

Imbatível em estudio

Legítimo e amigável

Honesto e agradável

Energético e eléctrico

Rebelde con ma

Médico é a profissão que eu quero ser

Elegante no vestido

( Guilherme, Brasil)

Tímida siempre que habla.

Idealista, quiere cambiar el mundo

Amable con todo el mundo

Nerviosa varias veces al día

(Tian, China) 


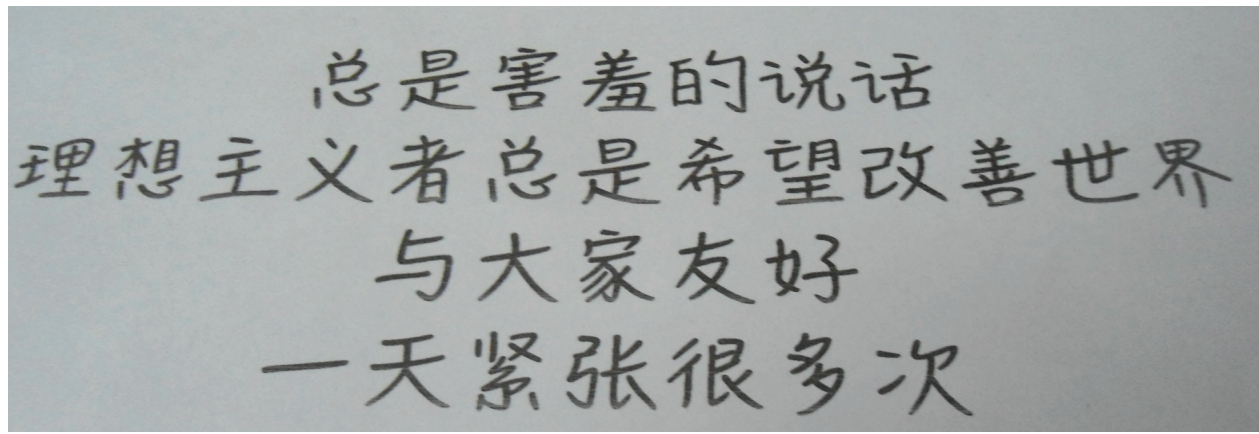

Imagen número 2, texto en chino

Después se pide al alumnado que elabore un texto poético que se titula "Yo soy". El alumnado tiene que escribir un texto en formato poema de verso libre que empiece con la expresión "yo soy", imaginándose que es: un continente, un país, una ciudad, un río, una montaña, un mar, un árbol, una comida, una lengua, una música, un instrumento musical, etc., y se pueden añadir otras cosas que cada cual desee. Con esta propuesta, por una parte se pretende poner en relación sus bagajes identitarios y también el campo semántico de Ciencias Sociales referente a lugares geográficos, magnitudes espaciales, etc., y en cada caso la frase acabará con por qué son esa montaña, ese mar, etc.

Un ejemplo de texto con "Soy":

Soy un continente, soy Europa porque mi madre está en Europa.

Soy un país, soy Senegal porque mi madre es senegalesa.

Soy una cuidad soy Dakar porque Dakar es mi ciudad en Senegal

Soy un río, soy Senegal porque Senegal es un río interesante.

Soy un océano soy el Océano Atlántico porque es muy grande.

Soy un mar soy "maritim" porque es un mar grande.

Soy un lago, soy el lago Retba porque es un lago interesante de Senegal

Soy una isla, soy la isla Gorée porque es una isla de Senegal

Soy una montaña, soy los Pirineos porque es una montaña de España.

Moussa, Senegal.

A continuación planteamos hacer el dibujo de su autorretrato, dado que el lenguaje plástico, el arte, es un lenguaje privilegiado para desarrollar la creatividad, la expresividad, el diálogo y conocer e interactuar con otras culturas.

Para hacer esta tarea, de nuevo establecemos relaciones con el área de Ciencias Sociales y el currículo de la educación secundaria, que exponemos a continuación de modo resumido, sin entrar en detalles de toda la secuencia didáctica de cómo se lleva a cabo por cuestiones de espacio: observamos y describimos algunas obras de la pintura occidental y española (Goya, Sorolla, Picasso,...), para lo que nos fijamos en algunas 
características de movimientos artísticos como el Impresionismo, el Cubismo y también en obras de arte y artistas de diferentes contextos culturales como Brancusi, Di Cavalcanti, Malévich,..., máscaras africanas o americanas, tejidos, cerámicas, etc. Se plantea como trabajo de investigación, realizando la búsqueda y selección de información a través de diferentes fuentes: Internet y las páginas web de diferentes museos: Musée du Quai Branly (Francia), Museo de Arte de Sao Paulo (Brasil ),Museo de América ( Madrid), el Museo Nacional de Arte chino de Pekin, galería Tretiakov( Moscú), el Museo sin fronteras, que tiene un amplio apartado de arte islámico, etc. La documentación que se va seleccionando por equipos o parejas, después se comparte con todo el grupo. También se realiza una visita al Museo de Bellas Artes de Oviedo, así como el visionado de vídeos y la consulta de libros de arte sobre el arte europeo, el arte en el mundo y cómo mirar una obra de arte. En este caso estamos abordando la comprensión de textos expositivos en diferentes formatos (escritos, audiovisuales, etc.) que guiamos a través de preguntas orales y/o escritas a partir de lecturas compartidas, bien en grupo clase, por parejas o en pequeños grupos. En este momento del proyecto también se abordan biografías de algunos/as artistas.

Entre las claves de cómo mirar y leer una obra de arte a través de algunos artistas y el arte de diferentes culturas, nos acercamos a la lectura de diferentes aspectos como:- los planos: primer plano, segundo plano, al fondo. En el caso de los retratos, los personajes pueden estar en primer plano (la cabeza), plano medio (hasta la cintura); plano americano (hasta la rodilla); plano entero (cuerpo entero);al léxico básico de técnicas de pintura: óleo, acuarela, lienzo,...,los colores, y leemos la obra de arte a partir de una ficha para describirla de modo denotativo y connotativo.

Ficha para la lectura de los retratos:

Primeras miradas

¿Qué vemos en la imagen?

¿Qué personaje hay? ¿Cómo es? ¿Qué ropa lleva?¿Cómo está ? ¿Dónde está? ¿Qué hace?

¿Qué colores, texturas,.. hay?

¿Qué tipo de imagen es? (una foto, una pintura,... )

¿Cómo crees que se siente?

¿Qué sientes tú al mirar el cuadro?

Documentación: completar una ficha informativa sobre la obra:

Título

Autor/a

Fecha

Técnica (óleo, grabado, acuarela...)

Hechos que representa

Significado/mensaje. 
La clase se organiza en grupos colaborativos, cuyos miembros son: críticos de arte, documentalistas y reporteros y trabajamos algunas claves de movimientos artísticos, muestras de arte de las diferentes culturas de la clase y planteamos algunas posibilidades de cómo mirar una obra de arte. Posteriormente visitamos el Museo de Bellas Artes de Oviedo para ver algunas obras o pintores sobre los que previamente investigamos en el aula como información previa a la realización de los autorretratos. Como en cada visita por la ciudad, el alumnado participa en todos los pasos: el uso del plano, concertar la cita, etc. Trabajamos con el plano de la ciudad, familiarizándonos con su lectura, el significado de los símbolos de la leyenda, etc., y localizamos el itinerario a realizar desde el instituto hasta el Museo. Concertamos la cita a través del teléfono, para lo cual, primero hacemos una simulación en clase de cómo dirigirnos a un organismo público por teléfono y después hacemos la llamada real. También pensamos, en grupo, qué preguntas plantearemos en el Museo. Algunas de las que sugirió el alumnado son las siguientes: ¿Se pueden hacer fotos?; otras están relacionadas con cómo orientarnos en el Museo:¿Dónde está la sala de pinturas de Goya?, etc. de este modo, durante la salida se produce una situación real de comunicación fuera del aula para practicar el nivel conversacional del español, por ejemplo cuando el alumnado pregunta a diferentes personas en la calle indicaciones para llegar al Museo. Aunque conocemos el itinerario a realizar sobre el plano, cuando estamos en la calle nos aseguramos de que vamos en la dirección correcta preguntando a diferentes personas, y afrontando situaciones nuevas de comunicación que no se habían previsto en la simulación en el aula, como cuando la respuesta que da alguna persona es que no sabe, o a su vez plantea una pregunta porque no está segura de dónde está, etc. 


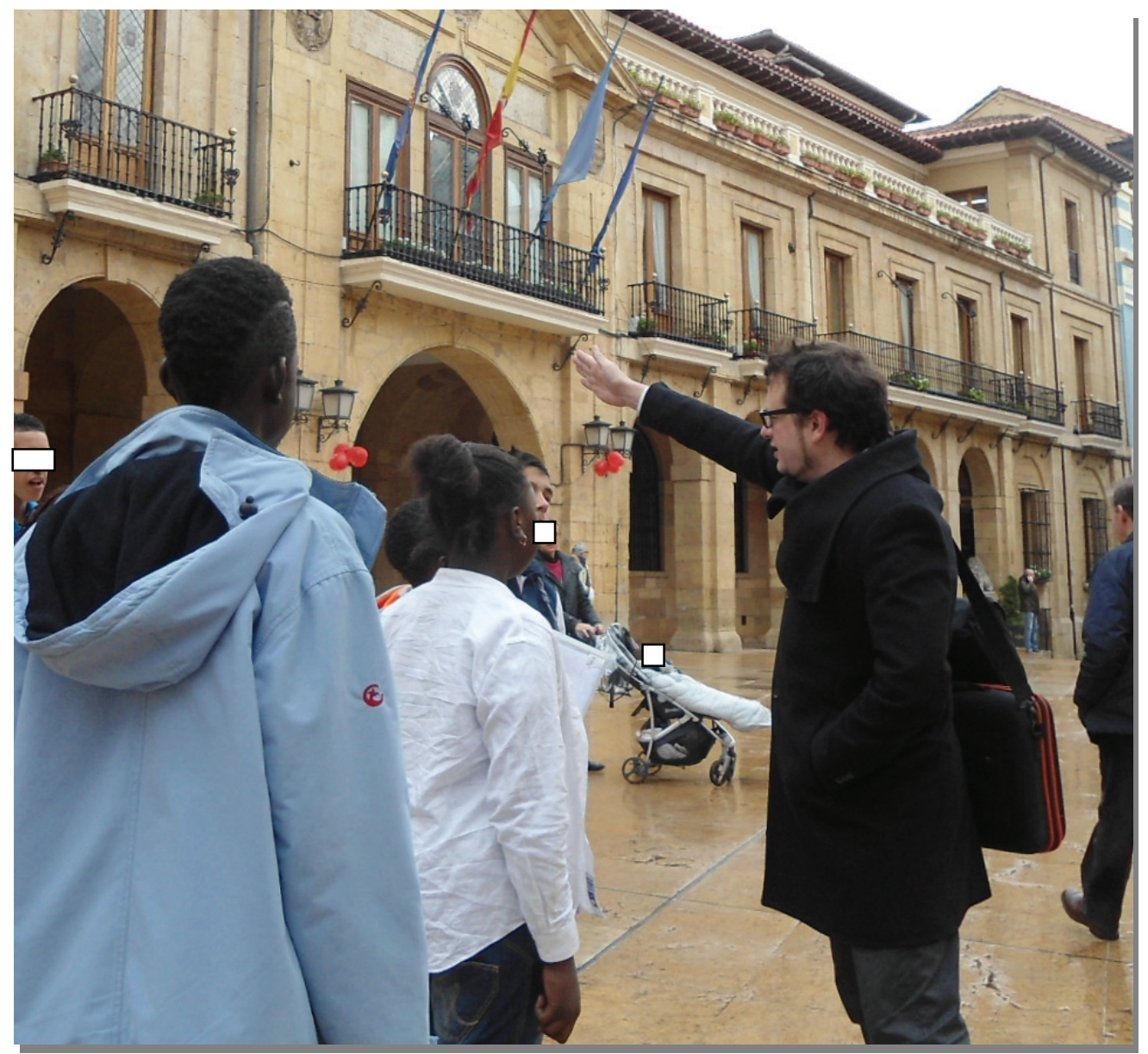

Imagen número 3.Solicitando indicaciones en la calle para llegar al Museo.

Dentro del Museo también podrán hacer un uso de la lengua conversacional al pedir la entrada, etc., y académico al observar los cuadros a partir de algunas explicaciones y de la ficha de trabajo que tienen que ir completando durante la visita. También emergen en este momento elementos de diálogo entre culturas, por ejemplo ante algunos cuadros con alguna referencia religiosa, o ante retratos de determinados personajes de piel negra, etc. 


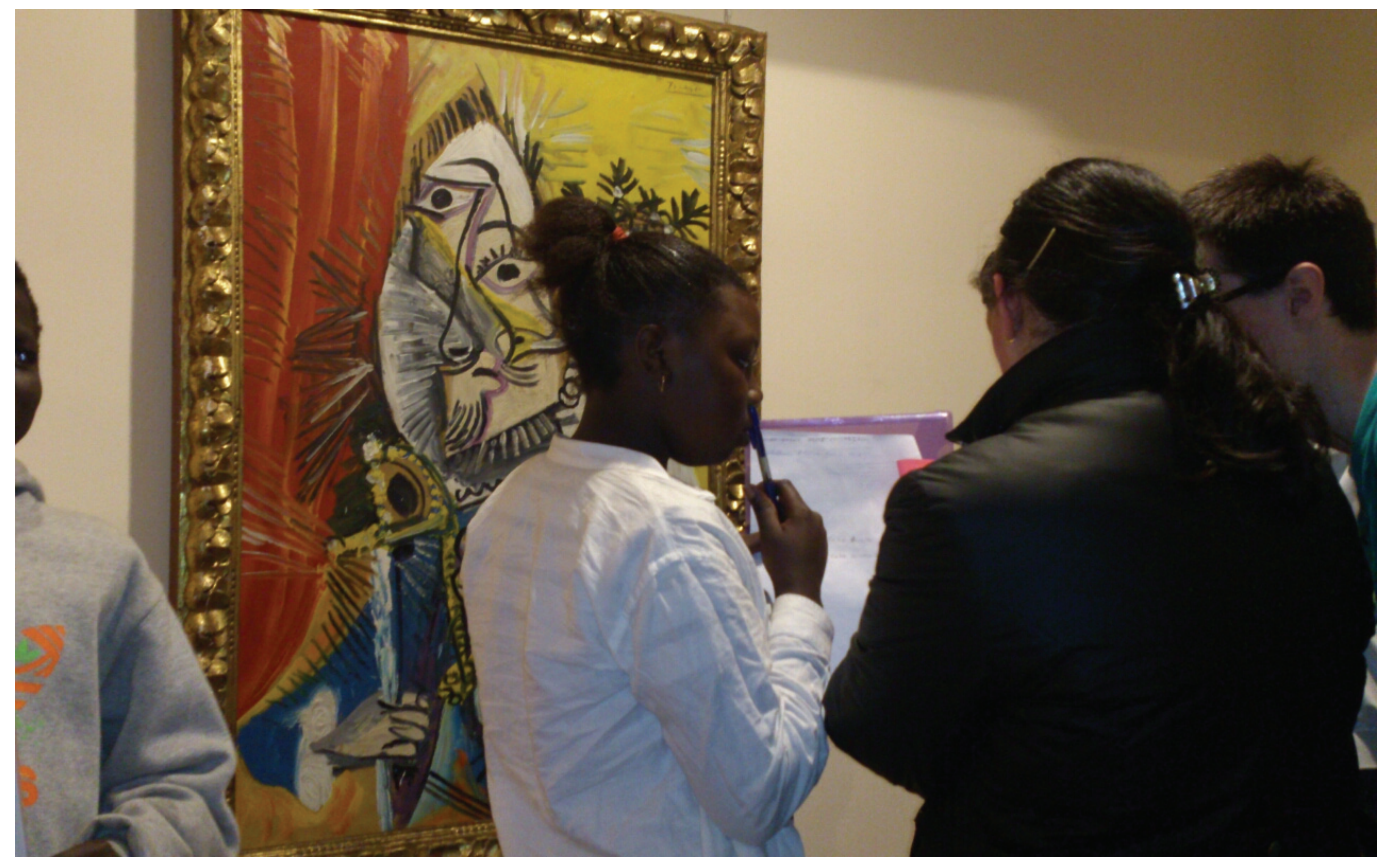

Imagen número 4. Observando un cuadro de Picasso en el Museo.

Después de este acercamiento al arte, a diferentes tipos de informaciones y de expresión artística de diferentes culturas, el alumnado realiza su autorretrato en un folio con lápices de colores. En su dibujo puede incluir también a alguna persona u objeto significativos para él/ella.

El último texto que escribimos en esta propuesta se titula "yo siento". Con el texto se pretende que el alumnado intente expresar algunas de las emociones o sensaciones que siente en este momento de su vida, y si es posible, dar alguna razón de por qué siente esa sensación o se siente así.

Para realizarlo revisamos conceptos y léxico básico de Ciencias Naturales que se menciona más arriba: los sentidos, los órganos de los sentidos, acciones, sensaciones, para poder expresar sentimientos, estados de ánimo, emociones. Como en los demás casos, se parte de los conocimientos previos del alumnado. Se realiza una lluvia de ideas a partir de los siguientes apartados: cuáles son los sentidos, los órganos de los sentidos, qué acciones se pueden hacer con ellos y qué se percibe. Todo lo que se va diciendo se escribe en la pizarra organizado en una tabla que se va elaborando entre todo el grupo, quedando una tabla a partir de la que después se realizan diferentes actividades de léxico, de descripciones, etc. 


\begin{tabular}{|c|c|c|c|}
\hline Sentidos & Órganos & Acciones & $\begin{array}{l}\text { Sensaciones } \\
\text { ( qué perciben) }\end{array}$ \\
\hline La audición y & El oído & Oír/escuchar & Los sonidos \\
\hline el equilibrio & & $\begin{array}{l}\text { Conocer la posición } \\
\text { del cuerpo y su } \\
\text { movimiento. }\end{array}$ & $\begin{array}{l}\text { Equilibrio estático y equilibrio } \\
\text { dinámico. }\end{array}$ \\
\hline La vista & Los ojos & Ver/mirar & Los colores, las formas,... \\
\hline El olfato & La nariz & Oler & Los olores \\
\hline El tacto & La piel & Tocar/sentir & $\begin{array}{l}\text { Las texturas } \\
\text { (suaves, rugosas, ásperas...; } \\
\text { La temperatura: frío/calor, templado }\end{array}$ \\
\hline El gusto & La lengua & Saborear & $\begin{array}{l}\text { Los sabores } \\
\text { (dulce, amargo, ácido, salado) } \\
\text { La temperatura de los alimentos: } \\
\text { frío/caliente. }\end{array}$ \\
\hline
\end{tabular}

Tabla1. Los sentidos

También se visionan algunos vídeos a partir de los que se afianzan conceptos, como el titulado "con los cuatro sentidos", en el que el protagonista es una persona ciega a la que se le organiza una celebración en la cual se percibe cómo disfruta de los cuatro sentidos que tiene.

Estos son algunos ejemplos de textos titulados

\section{Yo Siento...}

Con mis ojos negros veo baobabs de Senegal

Con mi lengua saboreo el thiebou dienne y el thiebou yapp que son salados y el helado de crema que es dulce.

Con mis oídos escucho música española,música francesa, y música wolof:

Youssou Ndour, Rihana, Akon,David Bisbal y One Direction

Con mi piel siento el mucho frío de Oviedo

Con mi nariz pequeña huelo un árbol de baobab.

$$
\text { Moussa, Senegal. }
$$

\section{Yo Siento}

Siento esperanza cuando veo mis ojos cuadrados.

Siento libertad cuando puedo hablar con mis labios rectangulares.

Siento tristeza cuando las lágrimas caen de mis ojos por mis mejillas cuadradas.

Huelo tarta de manzanas con mi nariz rectangular. 
Saboreo cozonac con mi boca rectangular.

Oigo sonidos de música por mis orejas triangulares.

Veo esculturas de Brancusi con mis ojos cuadrados.

Toco el piano con mis manos suaves y morenas.

Eduard, Rumanía.

A continuación recogemos los textos y un autorretrato de una alumna senegalesa. Es una muestra de la riqueza de vivencias que una persona puede expresar en una lengua nueva aun cuando está en un momento inicial del aprendizaje de la misma. Tal como hemos expuesto anteriormente, el trabajo final se realiza de modo individual, pero durante el proceso se recurre a la interacción oral siempre que hay una duda de cómo se dice en español alguna palabra o expresión, o cómo se escribe, etc., este tipo de dudas se procura resolver con la ayuda del grupo, y una forma de llevarlo a cabo es preguntando en lengua materna a otras compañeros que hablen esa misma lengua, o bien consultando al resto de la clase y a la profesora. Igualmente, para establecer relaciones entre oralidad y escritura, buscar coherencia textual se realizan reflexiones de forma compartida, unas veces por parejas y en otras ocasiones todo el grupo.

Presentamos algunos textos que comentaremos a continuación:

El acróstico:

Amable y simpática siempre.

Nerviosa en los exámenes

Tranquila y trabajadora, ayudo a mi familia

Abierta porque soy inteligente.

Le gusta bailar.

Ordenada porque está bien.

Única dibujando.

Músicas del mundo soy.

Anta, Senegal.

El acróstico en wolof, su lengua materna:

Bax ak yaru bis bu sett

Dama tit thi esamebi

Tok normal ak ligay ba mana dimbali samay wadiur

Man nama wax ak ñepu dax dama bax.

Bague na fethi

Damay defar samay bagass dax dafa baxx

Mannama disin te nexnama.

Damay degoulou wayi adunabiyepou

Yo soy

Yo soy un continente, soy África porque es mi continente. 
Yo soy un país, soy Senegal porque toda la gente hablamos wolof. Yo soy una ciudad, soy Touba porque todos son muridism. Yo soy un río, soy el río Gambia porque el río es azul. Yo soy un océano, soy el Océano Atlántico porque tiene olas grandes. Yo soy un mar, soy el mar Cantábrico porque está frío. Yo soy un lago, soy el lago Guer porque me baño cuando estoy en Senegal. Yo soy una isla, soy las islas Canarias porque tiene muchas islas verdes.

Yo soy una montaña, soy una montaña de España porque no son muy altas.

\section{Yo Siento}

Con mis ojos grandes y negros veo la mezquita de Touba.

Con mis oídos escucho música de Rihana y Justin Bieber.

Con mis manos toco el mar Cantábrico.

Con mi nariz huelo las rosas, los perfumes.

Con mi lengua saboreo el couscous y pescado con arroz.

Con mi piel siento el calor de Senegal y el frío de Asturias.

Me siento triste porque mi madre y mi hermana están en Senegal.

Me siento contenta porque estoy en España.

Me siento enfadada porque es fin de semana.

Me siento cansada porque trabajo en mi casa.

Me siento tranquila porque aprender bien español.

Me siento preocupada porque voy a estudiar en el Alfonso II.

Me siento sorprendida porque mi padre va a Senegal.

Me siento desanimada porque tengo mucho frío.

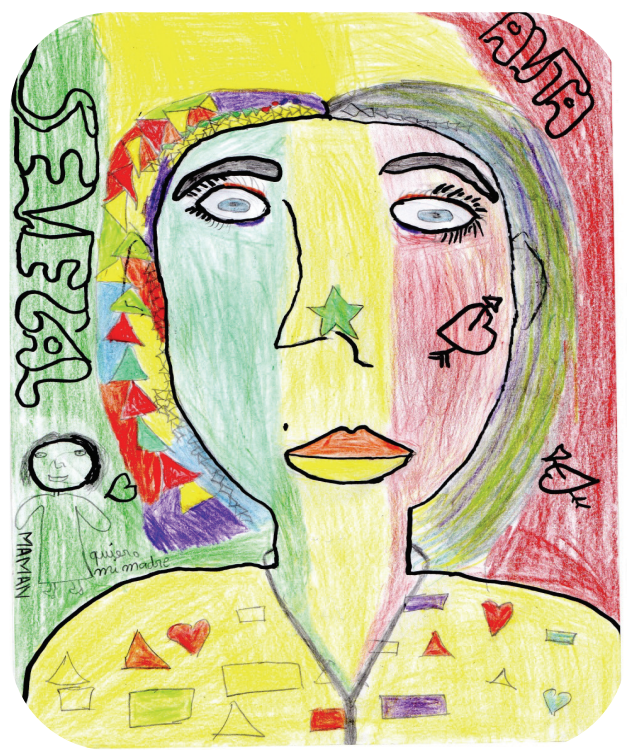


Imagen número 5

Queremos detenernos en lo que expresa esta alumna en algunos de los textos. Por ejemplo, al escribir el acróstico recoge algunas de las cuestiones con las que se identifica, como el baile y la música o ayudar a la familia. Escribir el texto no solo en español, sino también en wolof es algo que le ilusionó y ante lo que hizo algún comentario referente a cómo suenan en una y otra lengua las palabras que sirven para expresar lo mismo, de modo que realiza una reflexión metalingüística, y sobre todo, establece un puente emocional con elementos muy valiosos para ella, como su lengua materna.

El texto titulado "soy" muestra el dinamismo de la construcción de las identidades, que reflejan pertenencias múltiples, o al menos, vivencias con fuerte carga emocional de diferentes lugares del mundo donde vivió y donde vive. Es de Senegal, tiene imágenes de su país y de su ciudad, y sonidos, en sentido amplio, de algo tan importante como su lengua materna, y también elementos del nuevo paisaje en el que vive, como el mar Cantábrico.

En el texto "siento", expresa algunas sensaciones físicas, como el frío. Es una vivencia relevante para ella, pues implica tener que adaptarse a un clima muy distinto al de su país de origen, donde vivió hasta ahora. Y podemos constatar que es un factor que le ocasiona incomodidad, incluso la lleva a sentirse desanimada, y lo expresa en la última frase del poema. Llega todos los días a clase con mucho frío, no sabe exactamente qué calzado ponerse, porque le gusta sentir sus pies libres y no con botas cerradas, pero en el clima donde vive ahora es necesario abrigarse. También muestra "sorpresa" porque su padre va a Senegal (se marchó durante las semanas que trabajamos esta propuesta), y ella que acaba de llegar a España se queda aquí, y no puede ir a ver a su madre.

El dibujo del retrato está lleno de símbolos y anclajes emocionales: por una parte su rostro y sus características, por ejemplo las trenzas, además, tiene los colores de la bandera de Senegal y en tamaño pequeño está el dibujo de su madre, que aún está en Senegal, esta cuestión que también la expresa en una frase "estoy triste porque mi madre y mi hermana están en Senegal."

Recogemos otros dos retratos por la forma cómo a través del lenguaje plástico recrean sus identidades 


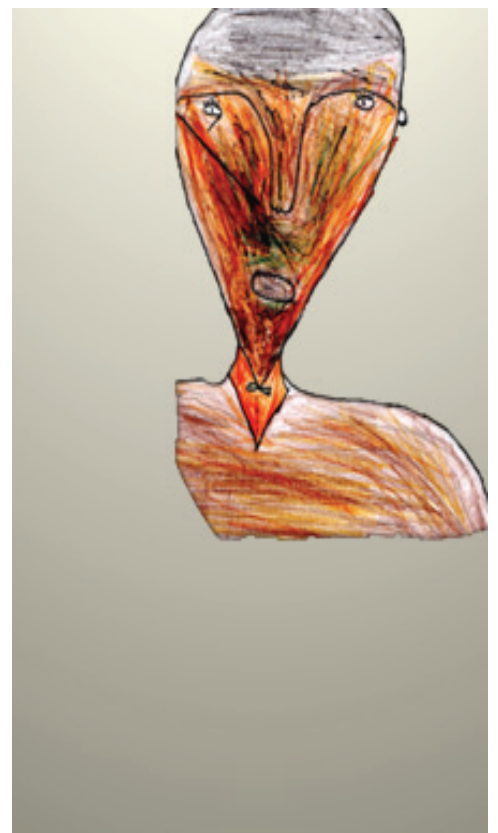

Imagen número 6

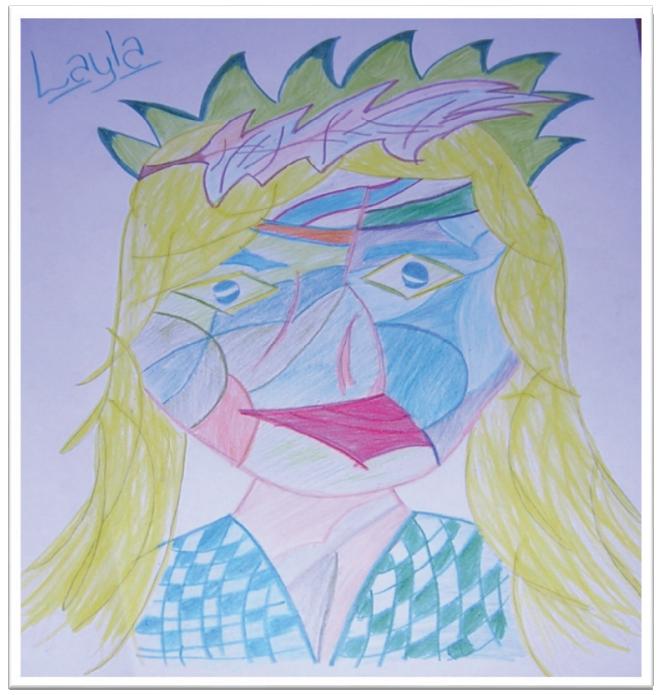

Imagen número 7

La imagen número 6 muestra la mezcla de colores para intentar conseguir un determinado color de piel, atributo que su autor considera relevante, tal como 
remarcaba mientras creaba el retrato, por lo que, aunque pueda considerarse un rasgo de racialización, en este caso, expresado claramente por el creador del retrato, supone autoafirmación

La imagen número 7 tiene varios elementos identitarios, entre otros, incorpora elementos de las máscaras americanas, o la bandera del país al que pertenece la autora del retrato.

Resumimos la secuencia didáctica del proyecto

\section{Tarea 1. ¿Quién soy?}

( Conexión con el área de Ciencias Sociales)
Tarea 1- Nombres e identidades. Nuestros nombres

- Aprendemos a dar los datos personales (nombre, edad, nacionalidad, lenguas que habla, etc.)

- Reflexionamos sobre nuestros nombres a partir de dos textos de Anne aquí, Sélima allá.

\section{Tarea1.b-identidades y pertenencias}

- Para expresar quienes somos incorporamos también información sobre pertenencias geográficas. Conocemos cómo se dice en español el nombre de algunos lugares, accidentes geográficos y diferentes magnitudes espaciales.

- Se realizan actividades interactivas orales y escritas sobre datos personales.

Texto final: Escribimos un acróstico con nuestro nombre

Descripción de personas por el aspecto físico y por el carácter

Lectura de: MOLINS RAICH, A. (2005) La opinión de los demás. Barcelona. La Galera (chino-español); El filósofo y el pescador. Barcelona. (españolárabe). Nos fijamos especialmente en la descripción de los personajes.

Texto final: escribir un poema de verso libre 


\begin{tabular}{|c|c|}
\hline & $\begin{array}{l}\text { titulado: Yo soy que refleje rasgos físicos, de } \\
\text { carácter, de pertenencias identitarias. }\end{array}$ \\
\hline $\begin{array}{l}\text { Tarea 3. Yo siento } \\
\text { ( Conexión con el área de Ciencias } \\
\text { Naturales ) }\end{array}$ & $\begin{array}{l}\text { Tarea 3.1.Sentidos y sensaciones } \\
\text { Tabla de sensaciones } \\
\text { Visionado del vídeo: Con los cuatro sentidos } \\
\text { Tarea 3.2 Emociones. } \\
\text { Expresar emociones a través del lenguaje verbal y } \\
\text { no verbal. } \\
\text { Texto final: escribir un poema de verso libre } \\
\text { titulado yo siento que recoja la expresión de } \\
\text { diferentes sensaciones y emociones personales. }\end{array}$ \\
\hline $\begin{array}{l}\text { Tarea 4. Conocemos obras de arte. } \\
\text { (Conexión con las áreas de Ciencias } \\
\text { Sociales y Expresión Plástica) }\end{array}$ & $\begin{array}{l}\text { Tarea 4. Conocemos obras de arte. (Retratos y } \\
\text { otras) } \\
\text { Claves para describir una obra de arte: } \\
\text { - Los planos } \\
\text { - Descripción denotativa y connotativa } \\
\text { Tarea 4.1 Primeras miradas } \\
\text { - Ficha para la descripción de una obra de } \\
\text { arte. Retratos. } \\
\text { Tarea 4.2-Documentación } \\
\text { Ficha informativa sobre una obra de arte } \\
\text { Investigación y presentación } \\
\text { En grupos de tres, consultan las direcciones de } \\
\text { Internet sobre museos, vídeos sobre Impresionismo } \\
\text { y Cubismo y los libros de arte del apartado recursos } \\
\text { y se buscan retratos, máscaras, etc., que representen } \\
\text { rostros o figuras humanas. Cada equipo selecciona } \\
\text { una obra y algún dato sobre un autor/a, y lo presenta } \\
\text { a la clase.(Ver el apartado recursos del proyecto } \\
\text { comunicARTE) } \\
\text { En cada equipo puede haber diferentes } \\
\text { especialistas: } \\
\text { - Críticos/as de arte: describen cómo es la } \\
\text { obra de arte elegida } \\
\text { - Documentalistas: recogen las fichas } \\
\text { - Rénicas de las obras } \\
\text { Rerteros/as: Recogen toda la }\end{array}$ \\
\hline
\end{tabular}




\begin{tabular}{|c|c|}
\hline & $\begin{array}{l}\text { información: escrita y de imágenes y la } \\
\text { presentan. }\end{array}$ \\
\hline $\begin{array}{l}\text { Tarea 5. Visita al Museo } \\
\text { (Conexión con las áreas de Ciencias } \\
\text { Sociales y Expresión Plástica) }\end{array}$ & $\begin{array}{l}\text { Visita al Museo de Bellas Artes de Oviedo. } \\
\text { Tarea 5.1.Preparación de la visita } \\
\text { Localización del Museo. Indicar en el plano el } \\
\text { recorrido a realizar desde el IES al Museo. } \\
\text { Realizar la localización en el plano en papel y en } \\
\text { Google maps. } \\
\text { Recordar cómo se pide información sobre una } \\
\text { dirección en la calle. } \\
\text { Selección de pintores y obras a visitar en el Museo: } \\
\text { Sorolla, Picasso. Buscar información en los recursos } \\
\text { web sobre las obras de estos pintores en el Museo } \\
\text { de Bellas Artes. } \\
\text { Tarea 5.2 Realización de la visita } \\
\text { En la calle preguntamos a algunas personas } \\
\text { dónde está el Museo para asegurarnos de } \\
\text { que estamos haciendo bien el recorrido. } \\
\text { - En el Museo se visitan las obras de, Evaristo } \\
\text { Valle, Piñole, El Greco, } \\
\text { Goya... Observamos especialmente las } \\
\text { obras de Picasso y de Sorolla. } \\
\text { - Completamos la ficha para la observación } \\
\text { en el Museo. } \\
\text { Tras la visita Puesta en común de la } \\
\text { experiencia. }\end{array}$ \\
\hline $\begin{array}{l}\text { Tarea 6. Mi autorretrato } \\
\text { ( Conexión con las áreas de Ciencias } \\
\text { Sociales y Expresión Plástica) }\end{array}$ & $\begin{array}{l}\text {-Realización plástica de los autorretratos. } \\
\text {-Preparación de un Power Point con los textos y los } \\
\text { dibujos de los autorretratos de cada alumno/a para } \\
\text { presentarlo al grupo clase. } \\
\text {-Montaje de un vídeo con los textos y los } \\
\text { autorretratos para difundirlo }\end{array}$ \\
\hline Tarea 7. ComunicARTE en el Museo & $\begin{array}{l}\text { El proyecto ComunicARTE y los trabajos del } \\
\text { alumnado se presentan en el Museo en el programa } \\
\text { Educación en el Museo para compartirlos con otros } \\
\text { centros educativos y en algunas sesiones de las }\end{array}$ \\
\hline
\end{tabular}


visitas guiadas para el público en general.

Tabla 2. Secuencia didáctica.

\subsection{Criterios y procedimientos de evaluación}

Planteamos una evaluación que proporcione información para ajustar la práctica educativa, es decir, que tenga en cuenta todos los elementos que inciden en el proceso de aprendizaje y que ayude al alumnado a autorregular sus aprendizajes. Se realiza una autoevaluación, una coevaluación con otros compañeros y la evaluación por parte de la profesora.

Uno de los instrumentos empleados es el Portfolio Europeo de las Lenguas (PEL) del que utilizamos especialmente la biografia lingüística y el dossier. La primera permite a cada alumno tomar conciencia de su acervo de lenguas y propicia que el grupo reflexione sobre la riqueza de la diversidad lingüística; y el segundo porque recoge las producciones del alumnado en diferentes formatos, permitiéndole percatarse de la evolución de sus aprendizajes. Un ejemplo de la biografía lingüística se recoge en el anexo 1.

Otros medios son los siguientes:

- La observación del trabajo diario en clase.

- El seguimiento de:

El cuaderno de trabajo y las tareas en formato digital.

Las actividades de lectura, de visionado de vídeos y de consulta de información en Internet.

Las exposiciones orales en clase.

La visita al Museo

- Una plantilla de criterios de evaluación

Estos aspectos pueden consultarse en la Web del proyecto ComunicARTE: https://sites.google.com/site/comunicartearteypalabras/proceso

\section{Consideraciones finales}

Con la realización de esta propuesta comprobamos la implicación del alumnado, su entusiasmo por comunicar, por buscar recursos expresivos para transmitir sus vivencias y dar a conocer referentes de sus anclajes en lugares geográficos diversos. El proyecto permite valorar el interés de las situaciones comunicativas auténticas dentro y fuera del aula. En el aula la interacción oral colaborativa entre iguales y con la profesora es una de las claves para negociar significados, para comprender los textos que trabajamos en diferentes formatos y para escribir los textos propuestos.

Se puede constatar la importancia de propiciar situaciones para establecer conexiones entre los propios bagajes del alumnado y el currículo académico como fuente de aprendizaje, de construcción de conocimiento de forma compartida, de 
motivación, de toma de conciencia de la diversidad cultural y de las propias identidades, que se construyen con múltiples pertenencias como transmiten con elocuencia los textos del alumnado. Y por lo tanto, que es necesario convertir este planteamiento en algo habitual en las propuestas

didácticas para que no queden en oasis inconexos, porque creemos que es un camino de enormes potencialidades para negociar significados, conocimientos y construcción de identidades, y comprobar que estas últimas están en constante dinamismo.

También se evidencia el gran interés que supone unir diferentes lenguajes, como defendía Malaguzzi, el de la palabra y el del arte entretejidos para sentir, pensar, mirar, aprehender y aprender el mundo. Tal como exponíamos más arriba, cada retrato, tanto a través de los textos como plástico, es un universo de aspectos particulares de cada alumno/a, de referentes de sus fondos de identidad y del patrimonio de una cultura. En definitiva, propicia el diálogo entre culturas y la diversidad lingüística, además de favorecer el desarrollo de la competencia comunicativa intercultural, académica y plurilingüe.

Finalmente, como exponíamos en las claves teóricas iniciales, hay que destacar el papel relevante que tiene el entorno, y, en concreto, algunos servicios culturales, como el que abordamos en este caso, el museo, como espacios de construcción intercultural, y podríamos decir que especialmente entre adolescentes y jóvenes. La incorporación de la mirada y la creatividad en mestizaje a través de ComunicArte en el Museo, es el siguiente paso de este proyecto que expondremos en otro momento.

\section{BIBLIOGRAFÍA}

AGUIRRE, I. (2003) Teorías y prácticas de la educación artística. Octaedro.

ANDRADE, R. (2007) ABC del continente africano.

AA. VV. (2001): La educación visual y plástica hoy. Educar la mirada, la mano y el pensamiento. Graó.

BANKS, J.A. (1992). Multicultural education: aproaches, developments and dimensions. En

J.LYNCH,C.MODGIL Y S.MODGIL (Ed.) Cultural diversity and the school. Londres: Falmer Press.

CAMPS, A.( Comp. )(2003) Secuencias didácticas para aprender a escribir. Graó. Barcelona.

CAMPS, A.; MILIAN, M. (2008) Miradas y voces. Investigación sobre la educación lingüistica y literaria en entornos plurilingües. Barcelona, Graó.

CASSANY, D. (2006) Tras las lineas. Barcelona, Anagrama.

CAUNE, J. (2009) "Prácticas culturales y modalidades de mediación. Construcción de un mundo en común y de las condiciones de convivencia" En Revista CIDOB, 88, pp. 13-24.Barcelona, Fundación CIDOB

CHALMERS, G. (2003) Arte, educación y diversidad cultural. Paidós 
COELHO, E.(2006). Enseñar y aprender en escuelas multiculturales. Una aproximación integrada. ICE- Horsori. Barcelona

COLOMER, T. (1997) La enseñanza y el aprendizaje de la comprensión lectora. Signos. Teoría y práctica de la educación, 20, 6-15. Gijón: CPR

CUMMINS, J. (2000) Lenguaje, poder y pedagogía. Niños y niñas bilingües entre dos fuegos, Madrid. Morata.

(2005b)" La hipótesis de la interdependencia 25 años después: la investigación actual y sus implicaciones para la educación bilingüe". En LASAGABASTER, D. Y SIERRA, J.M. (eds.)Multilingüismo, competencia lingüistica y nuevas tecnologías. Barcelona. Horsori. Pp.129-148.

DELMIRO COTO, B. (2002) La escritura creativa en las aulas. En torno a los talleres literarios. Barcelona. Graó(2008) Descubrir el arte a través del mundo.Factoría $\mathrm{K}$ de libros.

DICKINS, R. (2013)Historia del Arte. Una guía completa del arte occidental para principiantes. Usborne. Reino Unido.

ESTEBAN- GUITART, M.; VILA, I.(2013) Experiencias en educación inclusiva: vinculación familia, escuela y comunidad. Barcelona.Horsori.

FÉRAUD, M. (2006) Anne aquí, Selima allí. Madrid.Alfaguara.

FRANZÉ, A. Y MIJARES, L. (eds.).(1999). Lengua y cultura de origen: niños marroquies en la escuela Mediterráneo.

GARCÍA PAREJO, I.,(Coord.).(2011) Escribir textos expositivos en el aula. Fundamentación teórica y secuencias didácticas para diferentes niveles. Barcelona. Graó

JOLIBERT, J. (2001). "Formar niños lectores/productores de textos. Propuesta de una problemática didáctica integrada". En: BORAFULL, M.T., CEREZO, M: et al. Comprensión lectora. El uso de la lengua como procedimiento. (79-95) Barcelona. Graó.

KYMLICKA, W. (1996) Ciudadanía multicultural.Paidós. pp.136-37

MOLINS RAICH, A.(2005) La opinión de los demás. Barcelona. La Galera.

NEMIROVSKY, M. (2004) "La enseñanza de la lectura y de la escritura y el uso de soportes informáticos", en Revista iberoamericana de educación, $\mathrm{n}^{\circ} 36$, pp.105-112.

_(Coord.) (2009) Experiencias escolares con la lectura y la escritura.

Barcelona. Graó.

SHAUN TAN (2007) Emigrantes .Australia. Barbara Fiore editora

SOLÉ, I. (1999) Estrategias de lectura. Barcelona.Graó.

TAYLOR (1993) El multiculturalismo y "la política del reconocimiento". México. Fondo de Cultura Económica

TOLCHINSKY, L.; SIMÓ, R. (2001). Escribir y leer a través del currículo . Barcelona. Horsori 
UNAMUNO, V. (2003). Lengua, escuela y diversidad cultural. Hacia una educación lingüistica crítica. Barcelona. Graó.

VILA, I. (2006, b). "Lengua, escuela e inmigración”. Cultura y Educación, 18 (2), $127-142$.

WOLFE, G. (2004);Mira! El lenguaje corporal en la pintura. Serres. Barcelona

Vídeo: " Con los cuatro sentidos " [en línea] http://www.youtube.com/watch?v=yzrN8TO7H1k [consultado en diciembre de 2013].

\section{Anexo 1.}

1. Un ejemplo de la biografía lingüística de un alumno

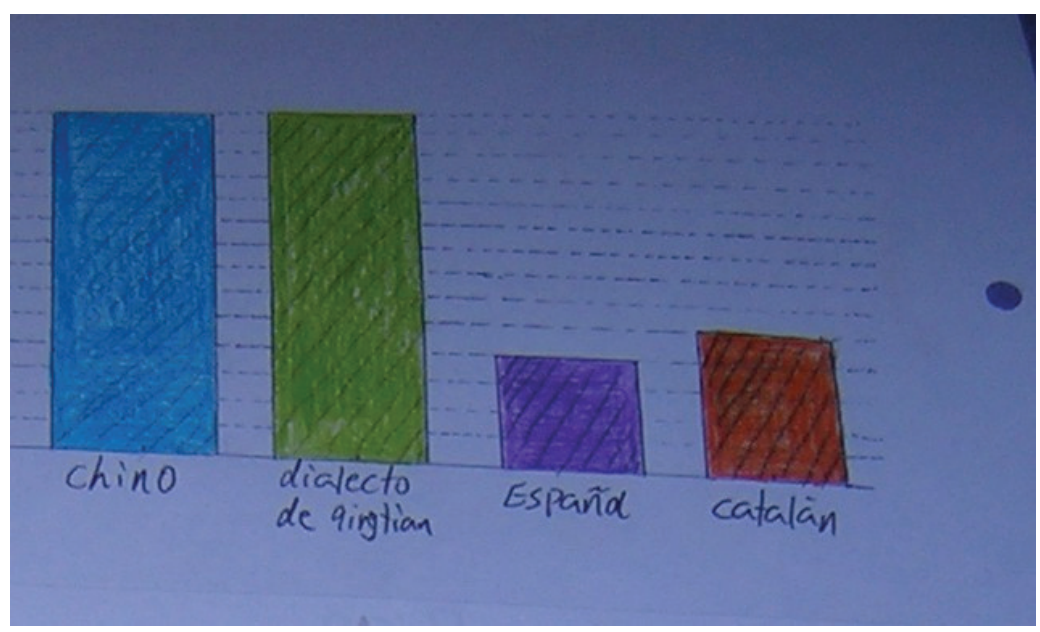

Las lenguas que habla. 


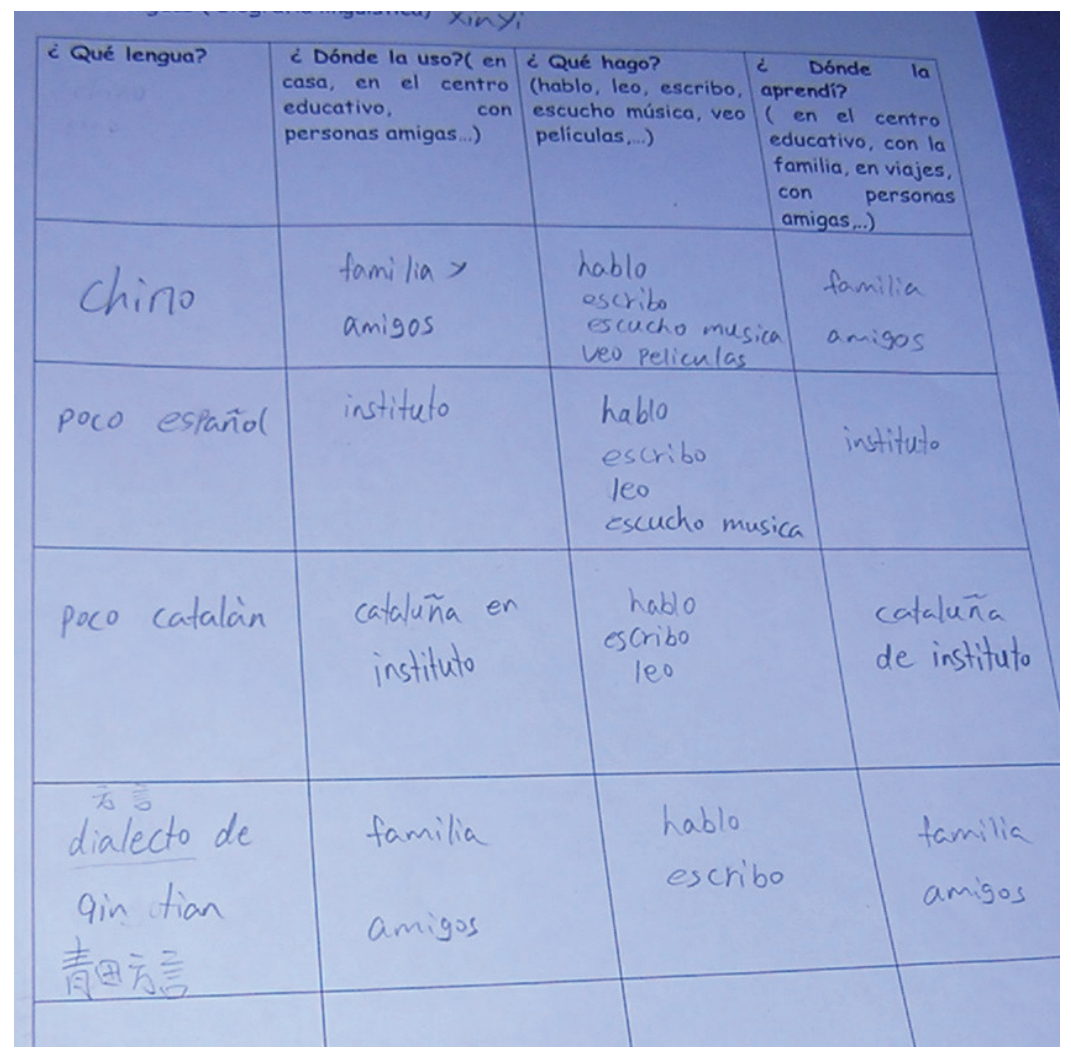

Lenguas que habla, qué sabe hacer con ellas y dónde y con quién las habla. 
Anexo2 Proceso de escritura de un texto sobre un pintor y poeta ruso

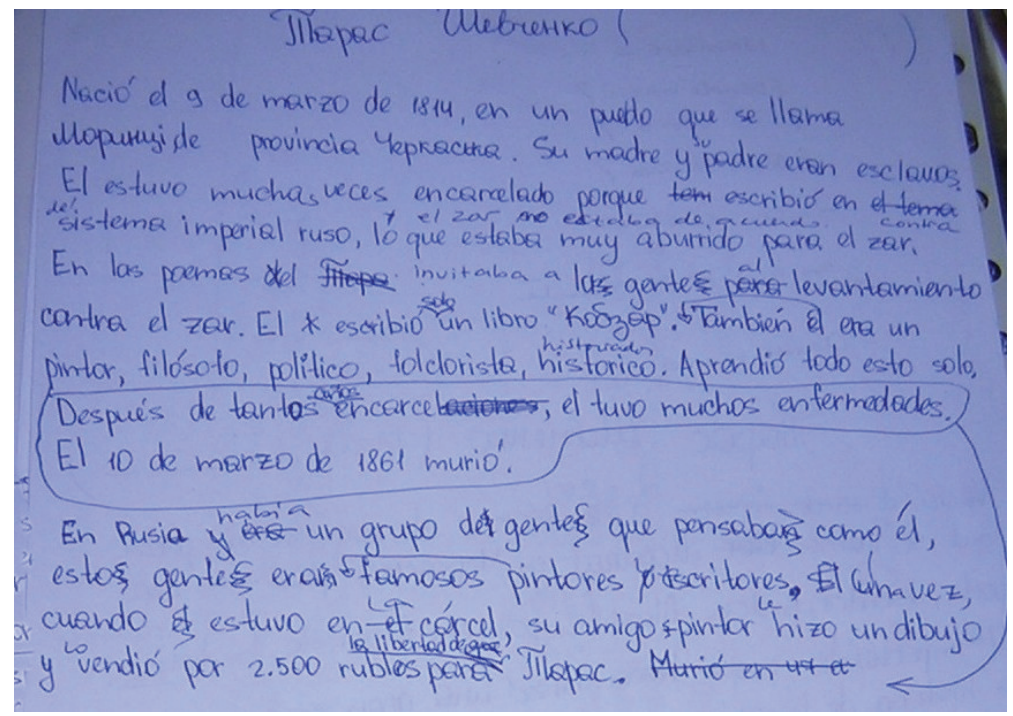

